\title{
Feasible and effective use of a simulation- based curriculum for post-graduate emergency medicine trainees in India to improve learner self-efficacy, knowledge, and skills
}

T. Ahluwalia ${ }^{1,2^{*}}$, S. Toy ${ }^{3}$, C. Gutierrez ${ }^{1,2}$, K. Boggs ${ }^{2}$ and K. Douglass ${ }^{4}$

\begin{abstract}
Background: Pediatric emergency medicine training is in its infancy in India. Simulation provides an educational avenue to equip trainees with the skills to improve pediatric care. We hypothesized that a simulation-based curriculum can improve Indian post-graduate emergency medicine (EM) trainees' self-efficacy, knowledge, and skills in pediatric care.

Methods: We designed a simulation-based curriculum for management of common pediatric emergencies including sepsis, trauma, and respiratory illness and pediatric-specific procedures including vascular access and airway skills. Training included didactics, procedural skill stations, and simulation. Measures included a self-efficacy survey, knowledge test, skills checklist, and follow-up survey. Results were analyzed using the Wilcoxon signed-rank test and paired-samples t test. A 6-month follow-up survey was done to evaluate lasting effects of the intervention.

Results: Seventy residents from four academic hospitals in India participated. Trainees reported feeling significantly more confident, after training, in performing procedures, and managing pediatric emergencies $(p<0.001)$. After the simulation-based curriculum, trainees demonstrated an increase in medical knowledge of $19 \%(p<0.01)$ and improvement in procedural skills from baseline to mastery of 18\%, 20\%, 16\%, and 19\% for intubation, bag-valve mask ventilation, intravenous access, and intraosseous access respectively $(p<0.01)$. At 6 -month follow-up, selfefficacy in procedural skills and management of pediatric emergencies improved from baseline.
\end{abstract}

Conclusions: A simulation-based curriculum is an effective and sustainable way to improve Indian post-graduate EM trainees' self-efficacy, knowledge, and skills in pediatric emergency care.

Keywords: Simulation, India, Pediatric emergency medicine, Procedures

\footnotetext{
* Correspondence: tahluwalia@childrensnational.org

'Division of Emergency Medicine, Children's National Medical Center, 111 Michigan Ave NW, Washington DC 20010, USA

${ }^{2}$ Department of Pediatrics, Children's National Medical Center, 111 Michigan Ave NW, Washington, DC 20010, USA

Full list of author information is available at the end of the article
}

(c) The Author(s). 2021 Open Access This article is licensed under a Creative Commons Attribution 4.0 International License, which permits use, sharing, adaptation, distribution and reproduction in any medium or format, as long as you give appropriate credit to the original author(s) and the source, provide a link to the Creative Commons licence, and indicate if changes were made. The images or other third party material in this article are included in the article's Creative Commons licence, unless indicated otherwise in a credit line to the material. If material is not included in the article's Creative Commons licence and your intended use is not permitted by statutory regulation or exceeds the permitted use, you will need to obtain permission directly from the copyright holder. To view a copy of this licence, visit http://creativecommons.org/licenses/by/4.0/ The Creative Commons Public Domain Dedication waiver (http://creativecommons.org/publicdomain/zero/1.0/) applies to the data made available in this article, unless otherwise stated in a credit line to the data. 


\section{Background}

Pediatric mortality in India is high, with an under-five mortality rate of 36.6 per 1000 live births as compared to 6.5 per 1000 live births in the USA [1]. Despite this, the subspecialty of pediatric emergency medicine (PEM) is in its infancy in India. PEM training is essential to equip physicians with knowledge and skills to manage acutely ill children. As emergency medicine (EM) training programs grow in India, progress is being made to enhance education related to management of pediatric emergencies.

Simulation allows trainees to practice skills, especially for low-frequency high impact critical events. Simulation-based training has been more effective than traditional approaches at increasing learners' satisfaction, knowledge, and skills [2]. With the need for specialized emergency care for children and the limited training availability in India, we have proposed the use of simulation to improve medical knowledge and procedural skills. Our primary objective is to improve Indian postgraduate EM trainees' self-efficacy, knowledge, and skills in pediatric care with the use of a simulation-based curriculum.

\section{Methods}

\section{Study setting and population}

This study was conducted at 4 academic hospitals in India. All trainees from each site were invited to participate.

\section{Study design and procedures}

The Ronald Reagan Institute of Emergency Medicine at the George Washington University has collaborated with partners in India for 14 years in 3-year post-graduate EM training programs [3, 4]. Training includes didactics, clinical rotations, research, and annual examinations. Pediatric emergency training includes 1-2 months per year of on-site education in India from visiting faculty from the USA, Canada, and UK. The 4 academic sites included in this study have received varying amounts of PEM simulation training based on equipment availability in the past. Our collaboration allowed for the provision of simulation equipment to 4 sites to allow for deliberate PEM training. Based on a needs assessment in 2019, completed by program directors, senior trainees, and visiting PEM faculty, we identified areas with the greatest knowledge gap and developed a corresponding simulation-based curriculum. This study included procedures (intravenous access (IV), intraosseous access (IO), bag-valve mask ventilation (BVM), intubation), and scenarios focused on septic shock, status asthmaticus, and blunt abdominal trauma. Education sessions took place over 2-3 days at each site.

\section{Educational intervention}

Visiting faculty were equipped with tools to lead simulations including video modules on how to conduct simulation; simulation cases from MedEd portal; simulation mannequins and equipment; and faculty support $[5,6]$. One of 4 visiting faculty members created the curriculum and it was run by the remaining faculty members at various sites. We used a validated simulation-based mastery learning framework for educational interventions to standardize training [7]. This consists of seven features: baseline testing, clear learning objectives, engagement of an educational activity, identified minimum standards to pass, formative testing, and continued practice until mastery-level achievement [7]. For procedural skills, trainees were provided with checklists of skill competencies (IV, IO, BVM, intubation). Checklists provided increased validity between evaluators by assessing concrete and measurable skills [8]. Participants practiced each skill until they met $100 \%$ of objectives (mastery) while being coached and evaluated by visiting faculty who used an evaluation checklist over 1 day.

Trainees were then divided into groups of 4-5 for simulation cases to apply their medical knowledge, as well as, practice their procedural skills. Each group included learners from each training year, with a thirdyear trainee as team leader. The participants must have been present during procedural skills training. The cases and associated procedures were septic shock (IO), status asthmaticus (IV), and pediatric blunt abdominal trauma (IV/BMV/intubation). After each case, there was a debriefing, followed by a post-questionnaire and posttest.

\section{Measures and data analysis}

We employed systematic training and evaluation guided by the Kirkpatrick 4-step framework to monitor this project's progress and to evaluate its effectiveness [9] (Table 1). This was a pre-test and post-test design whereby participants served as their own controls. Participants completed a survey measuring their self-efficacy in performing procedures (IV, IO, BVM, and intubation) and in managing pediatric emergencies, respiratory emergencies, trauma, and shock. We also collected demographic information including the number of prior procedures that they completed. Participants completed a knowledge test before and after the educational interventions to evaluate medical management. Additionally, they completed a procedural skills test after didactic training, and after reaching mastery for each skill to evaluate the impact of skills training. Additionally, a random subset of participants performed procedures during simulated cases, which were evaluated by independent raters using a checklist. We calculated percentage scores for 
Table 1 Kirkpatrick 4-step assessment model

\begin{tabular}{|c|c|c|}
\hline Level & Measurement & Measurement in this study \\
\hline 1 & Reaction: the degree that participants enjoyed the training & $\begin{array}{l}\text { Simulation evaluation forms: pre-questionnaire and post- } \\
\text { questionnaire }\end{array}$ \\
\hline 2 & $\begin{array}{l}\text { Learning: the degree that participants gained knowledge, skills, and confidence by } \\
\text { participating in the study }\end{array}$ & Skill evaluation forms: pre-test and post-test \\
\hline 3 & Behavior: the degree that participants applied what they gained from the training & $\begin{array}{l}\text { Skill evaluation forms during simulation and by 6-month } \\
\text { follow-up survey }\end{array}$ \\
\hline 4 & Results: the degree that targeted outcomes occur as a result of training & Six-month follow-up survey \\
\hline
\end{tabular}

the knowledge scores and number of completed procedural steps by dividing each participant's score by the maximum possible score, and these percentage scores were used in the analyses and reporting. Six months later, participants completed a follow-up survey to assess sustainability of skills and self-efficacy.

The self-report items regarding trainee self-efficacy were on an 11-point scale from 0 to 10 . Assumptions for parametric tests were not met for these average selfefficacy scores, as the Shapiro-Wilk's test was significant. Therefore, we compared these scores using the nonparametric Wilcoxon signed-rank tests. A set of paired samples $t$ tests were used to compare pre-test and posttest scores for knowledge, as well as, for procedural performance scores. All statistical analyses were conducted with Statistical Package for the Social Sciences (IBM SPSS Statistics for Mac, Version 25.0. Armonk, NY:IBM Corp.) with significance level set at $p<0.05$.

\section{Results}

Seventy EM trainees from four sites in India participated in the study. There were 28 trainees from Madurai (40\%), 16 from Kolkata (23\%), 16 from Mumbai (23\%), and 10 from Bhubaneswar (14\%). The majority of participants were males $(66 \%) ; 11 \%$ were in their first year of training, 39\% in their second year of training, and 50\% in their third year of training (Table 2). Fifty-seven trainees had prior simulation experience with

Table 2 Demographics

\begin{tabular}{cccccc}
\hline Variable & $\begin{array}{c}\text { Bhubaneswar } \\
(\boldsymbol{n}=\mathbf{1 0})\end{array}$ & $\begin{array}{l}\text { Kolkata } \\
(\boldsymbol{n}=\mathbf{1 6})\end{array}$ & $\begin{array}{l}\text { Madurai } \\
(\boldsymbol{n}=\mathbf{2 8})\end{array}$ & $\begin{array}{l}\text { Mumbai } \\
(\boldsymbol{n}=\mathbf{1 6})\end{array}$ & $\begin{array}{l}\text { Overall } \\
(\boldsymbol{n}=\mathbf{7 0})\end{array}$ \\
\hline $\begin{array}{l}\text { Gender, n (\%) } \\
\text { Female }\end{array}$ & $4(40 \%)$ & $5(31 \%)$ & $8(27 \%)$ & $7(44 \%)$ & $24(34 \%)$ \\
Male & $6(60 \%)$ & $11(69)$ & $20(71 \%)$ & $9(56 \%)$ & $46(66 \%)$ \\
Prior training, n (\%) & & & & \\
No & $9(90)$ & $15(94 \%)$ & $24(86 \%)$ & $16(100 \%)$ & $64(91 \%)$ \\
Yes & $1(10 \%)$ & $1(6 \%)$ & $4(14 \%)$ & - & $6(9 \%)$ \\
Training year, n(\%) & & & & \\
1 & - & $1(6 \%)$ & $7(25 \%)$ & - & $8(11 \%)$ \\
2 & $4(40 \%)$ & $7(44 \%)$ & $10(36 \%)$ & $6(37.5 \%)$ & $27(39 \%)$ \\
3 & $6(60 \%)$ & $8(50 \%)$ & $11(39 \%)$ & $10(62.5 \%)$ & $35(50 \%)$ \\
\hline
\end{tabular}

participants having placed up to $10 \mathrm{IVs}, 5 \mathrm{IOs}, 30 \mathrm{BVM}$, and 20 intubations. The total number of procedures performed in pediatric practice included 50 IVs, 2 IOs, 100 $\mathrm{BMV}$, and 30 intubations (Table 3).

Participants' felt significantly more confident, after training, in performing procedures and managing pediatric emergencies $(\mathrm{p}<0.001)$ (Table 4). Overall medical knowledge (all tests combined) increased from 61 to $80 \%(\mathrm{p}<0.01)$. A set of paired samples $\mathrm{t}$ tests indicated statistically significant improvement in knowledge scores for sepsis (pre-mean $=58 \%$, SD $=$ $23 \%$ vs post-mean $=80 \%, \mathrm{SD}=17 \%), \mathrm{t}(58)=-7.27$, $\mathrm{P}<.001$ ); and respiratory issues (pre-mean $=59 \%$, $\mathrm{SD}=24 \%$ vs post-mean $=81 \%, \mathrm{SD}=18 \%), \mathrm{t}(58)=-$ $6.07, \mathrm{P}<.001)$. Trauma knowledge also improved significantly, though with a much smaller magnitude, from the mean of $68 \%(\mathrm{SD}=29 \%)$ to $75 \%(\mathrm{SD}=$ $24 \%)(\mathrm{t}(58)=-2.10, \mathrm{p}=0.040)$.

Procedural skills from baseline to mastery increased by $18 \%, 20 \%, 16 \%$, and $19 \%$ for intubation, BVM, IV, and IO, respectively $(\mathrm{p}<0.01)$ (Table 5). Participants' procedural performance overall was better during the simulation compared to baseline scores except for IO skills, which decreased from 87 to $83 \%$ during simulation. Only significant skill gain was observed for BVM from baseline to simulation performance (baseline = $79 \%, \mathrm{SD}=21 \%$ vs sim-mean $=91 \%, \mathrm{SD}=13 \%), \mathrm{t}(7)$ $=-3.02, \mathrm{P}=.019)$. Please note the sample sizes are much smaller for these since we were not able to have all participants complete procedures during actual simulations.

Table 3 Previous experience with procedures

\begin{tabular}{lllll}
\hline Procedure & Median & Minimum & Maximum & Range \\
\hline \# IV SIM & 0 & 0 & 10 & 10 \\
\# IV Real Patient & 4 & 0 & 50 & 50 \\
\# IO Sim & 0 & 0 & 5 & 5 \\
\# IO Real Patient & 0 & 0 & 2 & 2 \\
\# BVM Sim & 2 & 0 & 30 & 30 \\
\# BVM Real Pt & 3 & 0 & 100 & 100 \\
\# Intubate Sim & 0 & 0 & 20 & 20 \\
\# Intubate Real Patient & 0 & 0 & 30 & 30 \\
\hline
\end{tabular}


Table 4 Self-reported self-efficacy

\begin{tabular}{|c|c|c|c|c|c|c|}
\hline \multirow[t]{2}{*}{ Variable } & \multicolumn{2}{|l|}{ Baseline } & \multicolumn{2}{|l|}{ Post-test } & \multirow[t]{2}{*}{$z$ value } & \multirow[t]{2}{*}{$p$ value } \\
\hline & Mean (SD) & Median & Mean (SD) & Median & & \\
\hline $\begin{array}{l}\text { Overall self-efficacy in performing } \\
\text { included procedures }\end{array}$ & $4.26(2.10)$ & 4.13 & $8.59(1.00)$ & 8.75 & -6.794 & $<0.001$ \\
\hline Overall self-efficacy in managing included pediatric emergencies & $4.69(1.95)$ & 4.88 & $8.13(1.05)$ & 8.00 & -6.793 & $<0.001$ \\
\hline
\end{tabular}

Mean, standard deviation, median, and Wilcoxon signed-ranks test results comparing overall self-efficacy between pretest and post-test scores in performing included procedures and managing pediatric emergencies $(n=61)$

Six months after the educational intervention, participants completed a follow-up survey. Results found that participants placed up to $20 \mathrm{IVs}$ in pediatric simulations and up to $50 \mathrm{IVs}$ in patients with an average self-efficacy of 7.18/10. Participants placed up to 10 IOs in pediatric simulations and up to 3 in patients, with an average selfefficacy of 5.5/10. Participants performed BVM in up to 30 simulated pediatric cases, and up to 30 patients, with an average self-efficacy of 8.75/10. Participants intubated up to 12 pediatric simulated patients and up to $30 \mathrm{pa-}$ tients, with an average self-efficacy of 6.92/10. Average self-efficacy for management of procedures and pediatric emergencies were 7.01 and 7.39, a sustained improvement over pre-intervention self-efficacy scores.

\section{Discussion}

We found that participants had the most experience with BVM and the least experience placing IOs in children. Procedural skills improved the most for BVM, which is likely due to targeted education on pediatric anatomical differences compared to adults. Airway and IV skills improved from baseline as compared to performance during simulation. Based on the follow-up survey, participants had the least self-confidence placing IOs. Further IO training would be useful. Overall, selfefficacy for management of pediatric emergencies improved after the intervention and sustained over time.

Interestingly, procedures were performed more clinically compared to a simulated environment except for IOs, which were only performed on 2 patients at baseline. In contrast, US trainees often practice procedural skills during simulation. Compared to previous studies implementing simulation in a low-resource environment, we found similar improvements in self-efficacy along with post-test score improvement [10].

Our simulation-based curriculum was an effective way to advance trainees self-efficacy, knowledge, and skills with pediatric procedures. We adapted cases based on the Indian context for this study. Further work to improve cultural competency around cases may also improve effectiveness. In this project, visiting faculty conducted the simulation program, and in the future, expanding this curriculum to a broader scale and developing projects focused on capacity building through faculty development among in-country partners may foster a sustainable future for PEM in India.

Table 5 Summary statistics for procedural skills at baseline and mastery and paired samples t test results

\begin{tabular}{|c|c|c|c|c|c|c|}
\hline Variable & $\mathbf{N}$ & Mean (SD) & Min & Max & $t$ & $p$ value \\
\hline \# of intubation attempts for mastery & 55 & $1.76(0.79)$ & 1 & 5 & & - \\
\hline Baseline \# of completed intubation steps & 56 & $9.79(2.76)$ & 0 & 12 & & - \\
\hline Baseline \% completed intubation steps & 56 & $82 \%(23 \%)$ & $0 \%$ & $100 \%$ & -6.00 & $<0.001$ \\
\hline Mastery \% completed intubation steps & 56 & $100 \%$ & $100 \%$ & $100 \%$ & & \\
\hline \# of BVM attempts for mastery & 56 & $1.64(0.72)$ & 1 & 4 & & - \\
\hline Baseline \# of completed BVM steps & 56 & $4.82(1.35)$ & 1 & 6 & & - \\
\hline Baseline \% completed BVM steps & 56 & $80 \%(22 \%)$ & $17 \%$ & $100 \%$ & -6.53 & $<0.001$ \\
\hline Mastery \% completed intubation steps & 56 & $100 \%$ & $100 \%$ & $100 \%$ & & \\
\hline \# of IV attempts for mastery & 54 & $2.02(1.54)$ & 1 & 10 & & - \\
\hline Baseline \# of completed IV steps & 55 & $5.87(1.26)$ & 0 & 7 & & - \\
\hline Baseline \% completed IV steps & 55 & $84 \%(18 \%)$ & $0 \%$ & $100 \%$ & -6.62 & $<0.001$ \\
\hline Mastery \% completed intubation steps & 55 & $100 \%$ & $100 \%$ & $100 \%$ & & \\
\hline \# of $1 \mathrm{O}$ attempts for mastery & 53 & $2.19(0.79)$ & 1 & 4 & & - \\
\hline Baseline \# of completed IO steps & 55 & $10.55(2.56)$ & 0 & 13 & & - \\
\hline Baseline \% completed IO steps & 55 & $81 \%(20 \%)$ & $0 \%$ & $100 \%$ & -7.11 & $<0.001$ \\
\hline Mastery \% completed intubation steps & 55 & $100 \%$ & $100 \%$ & $100 \%$ & & \\
\hline
\end{tabular}




\section{Limitations}

Our ability to install a sustained intervention was limited due to time constraints of visiting faculty in India. This study was also limited by low interrater reliability as we had different visiting faculty at various sites. We reported the number of procedures, as well as, self-efficacy in performing procedures and in management of pediatric emergencies at baseline, during, and at 6month follow-up. However, it is difficult to align the 6month follow-up directly with the study. Although we designed this study on Kirkpatrick's 4-step model, we were unable to assess outcomes on clinical care. Future studies on the translation to clinical care and patient outcomes would be valuable.

\section{Conclusion}

A simulation-based curriculum is an effective and sustainable way to improve Indian post-graduate EM trainees' self-efficacy, knowledge, and skills in pediatric emergency care.

\section{Abbreviations}

BVM: Bag-valve mask ventilation; EM: Emergency medicine; IV: Intravenous access; IO: Intraosseous access; PEM: Pediatric emergency medicine

\section{Acknowledgements}

The authors acknowledge Pavan Zaveri, Simone Lawson, Shobhit Jain, Rachael Batabyal, Michael Hardy, and Jacob Keller.

\section{Authors' contributions}

TA designed the study, conducted the study in India, interpreted results, and wrote the manuscript with input from all authors. ST designed the study, analyzed, and interpreted results. GC and KB conducted the study in India, discussed the results, and contributed to the manuscript. KD supervised all aspects of the project. All authors read and approved the final manuscript.

\section{Funding}

We were funded through the Global Health Institute at Children's National Hospital.

\section{Availability of data and materials}

The datasets used and/or analyzed during the current study are available from the corresponding author on reasonable request.

\section{Declarations}

\section{Ethics approval and consent to participate}

IRB Exempt from Children's National Hospital in Washington, DC. Consent to participate from all participants was included in this study.

\section{Competing interests}

The authors declare that they have no competing interests.

\section{Author details}

'Division of Emergency Medicine, Children's National Medical Center, 111 Michigan Ave NW, Washington DC 20010, USA. 'Department of Pediatrics, Children's National Medical Center, 111 Michigan Ave NW, Washington, DC 20010, USA. '3epartment of Anesthesiology and Critical Care Medicine, Johns Hopkins School of Medicine, Baltimore, USA. ${ }^{4}$ George Washington University School of Medicine and Public Health, Washington DC, USA.
Received: 7 February 2021 Accepted: 8 June 2021

Published online: 27 July 2021

\section{References}

1. India (IND) - Demographics, health \& infant mortality - UNICEF DATA [Internet]. [cited 2020 May 6]. Available from: https://data.unicef.org/ country/ind/]

2. Cook DA, Brydges R, Hamstra SJ, Zendejas B, Szostek JH, Wang AT, et al. Comparative effectiveness of technology-enhanced simulation versus other instructional methods: A systematic review and meta-analysis. Simul Healthc. 2012 Oct;7(5):308-20. https://doi.org/10.1097/SIH.0b013e3182614 f95

3. Douglass K, Pousson A, Gidwani S, Smith J. Postgraduate emergency medicine training in India: an educational partnership with the private sector. J Emerg Med. 2015 Nov 1;49(5):746-54. https://doi.org/10.1016/j. jemermed.2015.03.010

4. Partner Institutions | The Ronald Reagan Institute [Internet]. [cited 2020 May 6]. Available from: https://smhs.gwu.edu/reaganinstitute/international/india/ partners

5. MedEd Portal [cited 2020 May 15]. Available from: https://www.mededporta l.org

6. Simulation modules | Children's National [Internet]. [cited 2020 May 15]. Available from: https://childrensnational.org/news-and-events/video-gallery/ simulation-modules-intro

7. McGaghie WC. Mastery learning: it is time for medical education to join the 21 st century. Vol. 90, Academic Medicine. Lippincott Williams and Wilkins; 2015. p. 1438-41.

8. Whalen AM, Boyer DL, Nishisaki A. Checklist-based assessment of procedural skills: a missing piece in the link between medical education interventions and patient outcomes. Vol. 188, Journal of Pediatrics. Mosby Inc.; 2017. p. $11-3$

9. Kirkpatrick DL. Evaluating training programs. The Four Levels. Berrett-Koehler Organizational Performance Series [Internet]. 1994 [cited 2020 May 6]. Available from: http://search.ebscohost.com/login.aspx?direct=true\&db= eric\&AN=ED382790\&site=ehost-live\&scope $=$ site

10. Martinerie L, Rasoaherinomenjanahary F, Ronot M, Fournier P, Dousset B, Tesnière $A$, et al. Health care simulation in developing countries and lowresource situations. J Contin Educ Health Prof. 2018;38(3):205-12. https://doi. org/10.1097/CEH.0000000000000211.

\section{Publisher's Note}

Springer Nature remains neutral with regard to jurisdictional claims in published maps and institutional affiliations.
Ready to submit your research? Choose BMC and benefit from:
- fast, convenient online submission
- thorough peer review by experienced researchers in your field
- rapid publication on acceptance
- support for research data, including large and complex data types
- gold Open Access which fosters wider collaboration and increased citations
- maximum visibility for your research: over $100 \mathrm{M}$ website views per year
At $\mathrm{BMC}$, research is always in progress.
Learn more biomedcentral.com/submissions 